\title{
PENGARUH ORIENTASI KEWIRAUSAHAAN DAN ORIENTASI PASAR TERHADAP KINERJA PADA USAHA KECIL DAN MENENGAH SEKTOR RITEL
}

\author{
Mei Ie ${ }^{1}$, Vincent Pratama ${ }^{2}$ \\ ${ }^{1}$ Jurusan Manajemen, Universitas Tarumanagara Jakarta \\ Email:meii@fe.untar.ac.id \\ 2 Jurusan Manajemen, Universitas Tarumanagara Jakarta \\ Email:vincent@yahoo.com
}

Masuk : 19-06-2019, revisi: 19-06-2019, diterima untuk diterbitkan : 09-08-2019

\begin{abstract}
ABSTRAK
Sektor usaha kecil menengah (UKM) memiliki peran penting dalam mendorong pertumbuhan perekonomian Indonesia. Untuk menunjang kinerja UKM, diperlukan adanya orientasi kewirausahaan dan orientasi pasar. Tingkat orientasi kewirausahaan dalam bisnis dapat dilihat dari sejauhmana suatu bisnis/perusahaan berinovasi, mengambil resiko dan bertindak secara proaktif. Tingkat orientasi pasar dapat dilihat dari sejauhmana suatu bisnis/perusahaan fokus pada pelanggan (orientasi pelanggan), memahami pesaing (orientasi pesaing), dan mengintegrasi semua fungsi dalam bisnis/perusahaan untuk menciptakan nilai pelanggan yang unggul. Penelitian ini bertujuan untuk mengetahui pengaruh orientasi kewirausahaan dan orientasi pasar secara bersama-sama terhadap kinerja pada usaha kecil dan menengah sektor ritel, pengaruh orientasi kewirausahaan secara parsial terhadap kinerja pada usaha kecil dan menengah sektor ritel, dan pengaruh orientasi pasar secara parsial terhadap kinerja pada usaha kecil dan menengah sektor ritel. Metode pengambilan sampel yang digunakan dalam penelitian ini adalah non-probability sampling, dengan teknik purposive sampling. Data dianalisis dengan menggunakan metode analisis regresi ganda. Pengujian hipotesis menggunakan uji $\mathrm{F}$ dan ui t. Hasil pengujian hipotesis menunjukkan bahwa orientasi kewirausahaan dan orientasi pasar, baik secara bersama-sama maupun secara parsial memiliki pengaruh terhadap kinerja pada usaha kecil dan menengah sektor ritel. Kesimpulan dari penelitian ini adalah terdapat pengaruh orientasi kewirausahaan dan orientasi pasar secara bersama-sama terhadap kinerja pada usaha kecil dan menengah sektor ritel, terdapat pengaruh orientasi kewirausahaan secara parsial terhadap kinerja pada usaha kecil dan menengah sektor ritel, dan terdapat pengaruh orientasi pasar secara parsial terhadap kinerja pada usaha kecil dan menengah sektor ritel.
\end{abstract}

Kata kunci: orientasi kewirausahaan, orientasi pasar, kinerja, usaha kecil dan menengah

\begin{abstract}
The small and medium business sector (UKM) has an important role in driving the growth of the Indonesian economy. To support the performance of SMEs, an entrepreneurial orientation and a market orientation are needed. The level of entrepreneurial orientation in business can be seen from the extent to which a business / company innovates, takes risks and acts proactively. The level of market orientation can be seen from the extent to which a business / company focuses on customers (customer orientation), understands competitors (competitor orientation), and integrates all functions in the business / company to create superior customer value. This study aims to determine the effect of entrepreneurial orientation and market orientation together on performance in the small and medium sized retail sector, the effect of entrepreneurial orientation partially on performance in the small and medium sized retail sector, and the effect of partial market orientation on performance on businesses small and medium retail sector. The sampling method used in this study is non-probability sampling, with a purposive sampling technique. Data were analyzed using the multiple regression analysis method. Hypothesis testing using the $F$ test and UI $t$. The results of hypothesis testing show that entrepreneurial orientation and market orientation, both jointly and partially have an influence on performance in the retail and small businesses. The conclusion of this study is that there is an effect of entrepreneurial orientation and market orientation together on the performance of retail and small businesses in the retail sector, there is an effect of entrepreneurial orientation partially on performance in the retail and small businesses, and there is a partial influence of market orientation on performance in the retail and small business sector.
\end{abstract}

Keywords: entrepreneurship orientation, market orientation, performance, small and medium business. 


\section{PENDAHULUAN}

\section{Latar Belakang}

Sektor usaha kecil menengah (UKM) memiliki peran penting dalam mendorong pertumbuhan perekonomian Indonesia. Dengan adanya sektor UKM, pengangguran akibat angkatan kerja yang tidak terserap dalam dunia kerja menjadi berkurang. Selain itu dalam jangka waktu lima tahun terakhir, kontribusi UKM terhadap Produk Domestik Bruto (PDB) selalu di atas 50 persen serta kontribusi terhadap penyerapan tenaga kerja juga dinilai selalu berada di atas angka 90 persen (Herdiman, Agustus 2015). Namun masalah persaingan menjadi tantangan yang berat bagi pelaku UKM di Indonesia.

Untuk menghadapi persaingan yang makin berat tersebut, Hussain et. al. (2015) menyatakan bahwa para pemilik usaha memerlukan orientasi kewirausahaan dan orientasi pasar dalam menjalankan usahanya. Kedua hal tersebut diperlukan untuk dapat menyerap guncangan yang diakibatkan oleh lingkungan bisnis yang komplek dan juga dinamis serta membantu mereka dalam melihat dan memanfaatkan peluang-peluang bisnis.

Orientasi kewirausahaan dianggap sebagai penggerak yang penting dalam pertumbuhan serta kinerja yang unggul berkelanjutan (Kraus et. al., 2012; dalam Hussain et. al., 2015). Perusahaan yang memiliki orientasi kewirausahaan yang kuat dapat memiliki kemampuan untuk mencari dan mengeksploitasi kesempatan berinovasi di pasar (Lumpkin and Dess, 1996).

Kumar et al (2011; dalam Hussain et. al., 2015) berpendapat bahwa orientasi pasar dapat membimbing perusahaan mencapai keunggulan kompetitif yang berkelanjutan. Pemilik UKM diharapkan berorientasi kepada pasar untuk mempertahankan usahanya di lingkungan pasar yang kompetitif (Shehu, 2014).

Adapun tujuan penelitian ini adalah sebagai berikut:

a. Untuk mengetahui pengaruh orientasi kewirausahaan dan orientasi pasar secara bersamasama terhadap kinerja pada usaha kecil dan menengah sektor ritel.

b. Untuk mengetahui pengaruh orientasi kewirausahaan secara parsial terhadap kinerja pada usaha kecil dan menengah sektor ritel.

c. Untuk mengetahui pengaruh orientasi pasar secara parsial terhadap kinerja pada usaha kecil dan menengah sektor ritel.

\section{Tinjauan Literatur}

\section{Orientasi Kewirausahaan}

Orientasi kewirausahaan didefinisikan sebagai suatu proses pembentukan strategi dengan membuat organisasi memiliki tindakan dan keputusan yang berbasis kewirausahaan (Lumpkin \& Dess, 1996; Wiklund \&Shepherd, 2003; dalam Rauch et. al., 2004).

Orientasi kewirausahaan dapat juga diartikan sebagai strategi benefit perusahaan untuk dapat berkompetisi secara lebih efektif di dalam pasar yang sama (Porter, 2008; dalam Sinarasri, 2013).

Tingkat orientasi kewirausahaan dalam bisnis dapat dilihat dari sejauh mana suatu perusahaan berinovasi, mengambil resiko dan bertindak secara proaktif (Miller, 1983; dalam MatchabaHove \& Vambe, 2014). Secara spesifik, Miller mengidentifikasi dimensi dari orientasi kewirausahaan terdiri dari tiga, yaitu inovatif, pengambilan resiko dan proaktif. 
Kemudian, Lumpkin \& Dess (1996) menyempurnakan ide-ide orisinil yang dibuat oleh Miller tersebut dengan menambahkan dua aspek penting dalam orientasi kewirausahaan, yaitu agresifitas kompetitif dan otonomi (Lumpkin \& Dess, 1996).

Inovatif mengacu pada suatu sikap wirausahawan untuk terlibat secara kreatif dalam proses percobaan terhadap gagasan baru yang memungkinkan untuk menghasilkan suatu metode produksi baru sehingga dapat menghasilkan produk atau jasa baru, baik untuk pasar yang sudah ada sekarang maupun ke pasar baru. Semakin tinggi tingkatan inovatif dalam bisnis, semakin tinggi pula tingkatan orientasi kewirausahaan dalam bisnis (Botha \& Nyanjom, 2011; dalam Matchaba-Hove \& Vambe, 2014).

Lumpkin \& Dess (1996; dalam Hussain et. al., 2015) menganggap pengambilan resiko sebagai kualitas perusahaan yang sangat penting dalam menunjang kelangsungan, pertumbuhan dan kinerja terbaik perusahaan. Pengambilan resiko dapat didefinisikan sebagai kesediaan perusahaan dalam merebut kesempatan, meskipun perusahaan tidak tahu apakah usaha ini akan berhasil atau tidak, dan kesediaan perusahaan untuk bertindak dengan berani tanpa mengetahui konsekuensinya (Lumpkin \& Dess, 2001; dalam Matchaba-Hove \& Vambe, 2014).

Proaktif melibatkan pandangan berorientasi masa depan yang terlihat dalam tindakan yang diambil untuk mengantisipasi permintaan di masa mendatang (Casillas et al., 2010; Covin \& Slevin, 1989; Miller, 1983; dalam Matchaba-Hove \& Vambe, 2014). Beberapa studi menemukan bahwa perusahaan yang proaktif berusaha untuk memperkenalkan produk terbaru di pasar di depan pesaing mereka (Venkatraman, 1989; dalam Kusumawardhani dkk., 2009).

Menurut Lumpkin \& Dess (1996), agresifitas kompetitif mengacu pada kecenderungan wirausaha untuk secara langsung menantang pesaingnya secara kompetitif untuk memasuki pasar, memperbaiki posisi, mengungguli pesaing di pasar. Rauch et. al. (2004) mengatakan bahwa agresifitas kompetitif merupakan suatu upaya perusahaan untuk mengungguli kompetitornya, yang ditandai dengan postur yang ofensif atau respon yang agresif terhadap ancaman kompetitif.

Otonomi mengacu pada tindakan independen dari individu atau tim di menciptakan ide atau visi dan membawanya sampai selesai (Lumpkin \& Dess, 1996). Otonomi yang ditawarkan oleh perusahaan akan memotivasi karyawan untuk bekerja dengan cara yang positif yang dapat meningkatkan kinerja perusahaan. (Protas, 2008; dalam Kusumawardhani dkk., 2009)

\section{Orientasi Pasar}

Narver \& Slater (1990) yang mengatakan bahwa orientasi pasar merupakan suatu budaya organisasi yang paling efisien dan efektif untuk menciptakan perilaku-perilaku yang dibutuhkan untuk menciptakan nilai terbaik dari pelanggan dan kinerja yang unggul untuk bisnis.

Orientasi pasar dapat didefinisikan juga sebagai perilaku berupa identifikasi dan memahami kebutuhan pelanggan dengan tujuan untuk memberikan kepuasan pelanggan yang lebih dari pesaingnya (Lee et. al., 2006; dalam Shehu, 2014).

Menurut Narver dan Slater (1990) orientasi pasar terdiri dari fokus pada pelanggan (orientasi pelanggan), pemahaman terhadap pesaing (orientasi pesaing), dan integrasi dari semua fungsi dalam perusahaan untuk menciptakan nilai pelanggan yang unggul (koordinasi interfungsional). 
Orientasi pelanggan adalah memahami pembeli untuk dapat menciptakan nilai superior bagi mereka secara terus-menerus (Narver \& Slater, 1990). Orientasi pelanggan menuntut pemilik bisnis memahami seluruh kebutuhan pembeli (Day \& Wensley, 1988; dalam Narver \& Slater, 1990).

Orientasi pesaing mengacu pada memahami kelemahan dan kekuatan dari kompetitor, memberikan nilai superior kepada pelanggan dan mengalahkan pesaing (Kumar et al., 2011; Narver and Slater, 1990; dalam Hussain et. al., 2015).

Koordinasi interfungsional mengacu pada koordinasi antara semua departemen dan area fungsional perusahaan untuk memanfaatkan sumber daya organisasi dalam rangka menciptakan nilai superior bagi pelanggan (Hussain et al., 2015). Koordinasi interfungsional didefinisikan sebagai pemanfaatan terkoordinasi sumber daya perusahaan dalam menciptakan nilai superior kepada pelanggan (Narver \& Slater, 1990).

\section{Kinerja Usaha}

Kinerja usaha didefinisikan sebagai kemampuan perusahaan untuk membuat tindakan dan hasil yang dapat diterima (Pfeffer \& Salancik, 1978; dalam Samir \& Larso, 2011).

Matchaba-Hove \& Vambe (2014) mendefinisikan kinerja usaha sebagai suatu bisnis yang menunjukkan pertumbuhan dalam laba dan dapat mencapai tujuan secara finansial. Penelitian sebelumnya menyatakan bahwa pertumbuhan penjualan perusahaan merupakan indikator kinerja yang paling umum (Barkham et al., 1996: dalam Matchaba-Hove \& Vambe, 2014).

Suliyanto dan Rahab (2012) mengukur kinerja usaha dari pertumbuhan profit, peningkatan volume penjualan, peningkatan jumlah pelanggan, peningkatan jumlah karyawan, penurunan jumlah keluhan dan pencapaian produk ke pasar yang lebih luas.

\section{Keterkaitan Orientasi Kewirausahaan dan Orientasi Pasar terhadap Kinerja Usaha}

Penelitian yang dilakukan di Johor, Malaysia oleh Hussain et. al. (2015) menunjukkan bahwa orientasi kewirausahaan (proaktif, inovatif, pengambilan resiko, otonomi dan agresifitas kompetitif) dan orientasi pasar (orientasi pelanggan, orientasi pesaing dan koordinasi interfungsional) memberikan pengaruh positif terhadap kinerja organisasi.

Penelitian yang dilakukan oleh Matchaba-Hove \& Vambe (2014) di Eastern Cape, Afrika Selatan menunjukkan bahwa dimensi orientasi kewirausahaan (inovatif, proaktif, dan agresifitas kompetitif) berpengaruh positif terhadap kinerja usaha, sedangkan pengambilan resiko dan otonomi tidak memberikan pengaruh yang signifikan terhadap kinerja perusahaan. Hasil penelitian yang dilakukan oleh Keh et. al. (2007) menunjukkan bahwa orientasi kewirausahaan memiliki pengaruh positif terhadap kinerja usaha.

Orientasi pasar juga memberikan hubungan positif terhadap profitabilitas usaha (Narver \& Slater, 1990). Penelitian sebelumnya juga menunjukkan adanya pengaruh positif orientasi pasar terhadap kinerja usaha pada perusahaan high-tech di Kazan (Protcko \& Dornberger, 2014).

Hipotesis Penelitian

Adapun hipotesis penelitian adalah sebagai berikut:

H1 : Orientasi kewirausahaan dan orientasi pasar secara bersama-sama berpengaruh terhadap kinerja pada usaha kecil dan menengah sektor ritel. 
$\mathrm{H} 2$ : Orientasi kewirausahaan secara parsial berpengaruh terhadap kinerja pada usaha kecil dan menengah sektor ritel.

H3 : Orientasi pasar secara parsial berpengaruh terhadap kinerja pada usaha kecil dan menengah sektor ritel.

\section{Rumusan Masalah}

Adapun rumusan masalah dalam penelitian ini adalah sebagai berikut:

a. Apakah orientasi kewirausahaan dan orientasi pasar secara bersama-sama mempengaruhi kinerja pada usaha kecil dan menengah sektor ritel ?

b. Apakah orientasi kewirausahaan secara parsial mempengaruhi kinerja pada usaha kecil dan menengah sektor ritel ?

c. Apakah orientasi pasar secara parsial mempengaruhi kinerja pada usaha kecil dan menengah sektor ritel?

\section{METODE PENELITIAN}

Populasi pada penelitian ini adalah seluruh wirausaha skala kecil dan menengah di Jakarta Barat. Metode pengambilan sampel yang digunakan dalam penelitian ini adalah non-probability sampling, dengan teknik purposive sampling. Sampel dalam penelitian ini sebanyak tiga puluh orang wirausahawan pemilik usaha skala kecil dan menengah sektor ritel di Kembangan, Jakarta Barat. Kriteria sampel dalam penelitian ini adalah UKM yang berada di Jakarta Barat dengan lama usaha minimal satu tahun.

Roscoe (1975, dalam Sekaran \& Bougie, 2013) menyatakan bahwa ukuran sampel paling tidak harus beberapa kali lebih besar (sepuluh kali atau lebih) dari jumlah variabel yang diteliti dalam penelitian. Dalam penelitian ini akan diambil sampel sebanyak tiga puluh orang wirausaha pada usaha kecil dan menengah sektor ritel.

Dimensi-dimensi yang digunakan untuk mendapatkan data tanggapan responden adalah sebagai berikut :

a. Orientasi kewirausahaan diukur dari lima dimensi, yaitu inovatif, pengambilan resiko, proaktif, agresifitas kompetitif, dan otonomi yang indikator-indikatornya diadopsi dari Lotz \& Merwe (2013), Wang (2008), dan Lumpkin \& Dess (2001).

b. Orientasi pasar diukur dari tiga dimensi, yaitu orientasi pelanggan, orientasi pesaing, dan koordinasi interfungsional, yang indikator-indikatornya diadopsi dari Jhonson et. al. (2009) dan Shehu (2014).

c. Kinerja usaha diukur dari lima indikator, yang diadopsi dari Suliyanto \& Rahab (2012) dan Farrington et. al. (2009), yang terdiri dari pertumbuhan profit, peningkatan volume penjualan, peningkatan jumlah pelanggan, peningkatan jumlah karyawan, dan penurunan jumlah keluhan.

Untuk menganalisis data, peneliti menggunakan analisis regresi ganda yang bertujuan untuk menguji pengaruh variabel orientasi kewirausahaan dan orientasi pasar terhadap kinerja pada usaha kecil dan menengah sektor ritel.

Untuk menguji hipotesis penelitian, dilakukan dengan uji $\mathrm{F}$ dan uji t. Jika nilai signifikansi kurang dari 0.05, maka variabel independen (orientasi kewirausahaan dan orientasi pasar) yang diuji dinyatakan memiliki pengaruh terhadap kinerja usaha (Ghozali, 2012). 


\section{HASIL DAN PEMBAHASAN}

Hasil Analisis Data

Berikut adalah hasil pengolahan data dengan menggunakan analisis regresi ganda:

Tabel 1. Hasil Analisis Regresi Ganda

\begin{tabular}{|l|r|r|r|}
\hline \multirow{2}{*}{ Model } & \multicolumn{2}{|c|}{ Unstandardized Coefficients } & \multicolumn{2}{c|}{ Standardized Coefficients } \\
\cline { 2 - 4 } & $\mathrm{B}$ & Std. Error & \multicolumn{1}{c|}{ Beta } \\
\hline (Constant) & -.197 & 2.776 & .362 \\
Orientasi Kewirausahaan & .140 & .056 & .533 \\
Orientasi Pasar & .331 & .090 & \\
\hline
\end{tabular}

a. Dependent Variable: Kinerja Usaha

Tabel 2. Uji F

\begin{tabular}{|c|c|c|c|c|c|c|}
\hline \multicolumn{7}{|c|}{$\mathrm{ANOVA}^{\mathbf{a}}$} \\
\hline & & Sum of Squares & $\mathrm{df}$ & Mean Square & $\mathrm{F}$ & Sig. \\
\hline \multirow{3}{*}{1} & Regression & 160.857 & 2 & 80.429 & 26.319 & $.000^{\mathrm{b}}$ \\
\hline & Residual & 82.509 & 27 & 3.056 & & \\
\hline & Total & 243.367 & 29 & & & \\
\hline
\end{tabular}

a. Dependent Variable: Kinerja Usaha

b. Predictors: (Constant), Orientasi Pasar, Orientasi Kewirausahaan

Pada tabel 2, menunjukkan bahwa angka signifikansinya sebesar 0.000. Oleh karena nilai signifikansinya kurang dari 0.05 , maka H1 diterima, artinya orientasi kewirausahaan dan orientasi pasar secara bersama-sama memiliki pengaruh terhadap kinerja pada usaha kecil dan menengah sektor ritel dengan tingkat keyakinan $95 \%$.

Tabel 3. Uji t

\begin{tabular}{|l|r|r|}
\hline Model & $\mathrm{t}$ & \multicolumn{1}{|c|}{ Sig. } \\
& & \\
\hline (Constant) & -.071 & .944 \\
1 Orientasi Kewirausahaan & 2.487 & .019 \\
Orientasi Pasar & 3.666 & .001 \\
\hline
\end{tabular}

a. Dependent Variable: Kinerja Usaha

Pada tabel 3, dapat dilihat bahwa nilai signifikansi pada orientasi kewirausahaan sebesar $0.19<$ 0,05, yang berarti $\mathrm{H} 2$ diterima, sehingga dapat dinyatakan bahwa orientasi kewirausahaan secara parsial memiliki pengaruh terhadap kinerja pada usaha kecil dan menengah sektor ritel dengan tingkat keyakinan $95 \%$.

Pada tabel 3, dapat dilihat juga bahwa orientasi pasar memiliki nilai signifikansi sebesar 0.001 . Angka signifikansinya kurang dari 0,05, yang berarti H3 diterima, sehingga dapat dinyatakan 
bahwa orientasi pasar secara parsial memiliki pengaruh terhadap kinerja pada usaha kecil dan menengah sektor ritel dengan tingkat keyakinan $95 \%$.

\section{Pembahasan}

Hasil pengujian dari uji $\mathrm{F}$ menunjukkan bahwa orientasi kewirausahaan dan orientasi pasar secara bersama-sama memiliki pengaruh terhadap kinerja pada usaha kecil dan menengah sektor ritel dengan nilai signifikansi sebesar $0.000<0.05$. Hasil pengujian ini mendukung penelitian sebelumnya yang dilakukan oleh Hussain et. al. (2015) dan Gonzalez-Benito (2009; dalam Hussain et. al., 2015) yang menyatakan bahwa orientasi kewirausahaan dan orientasi pasar secara bersama-sama mempengaruhi kinerja perusahaan.

Hussain et. al. (2015) menyatakan bahwa orientasi pasar dapat membantu perusahaan dalam membuat nilai terbaik pada pelanggan, mengungguli pesaing dan meningkatkan kinerja perusahaan, sedangkan orientasi kewirausahaan dapat membantu perusahaan dalam mencari dan mengeksploitasi peluang-peluang di pasar dimana pesaing tidak dapat meraihnya, mengambil resiko dan memperkenalkan produk baru dengan tujuan untuk mencapai keunggulan yang berkelanjutan.

Berdasarkan dari hasil uji t yang dilakukan dalam penelitian ini, variabel orientasi kewirausahaan yang tercermin dari sikap inovatif, pengambilan resiko, proaktif, agresifitas kompetitif dan otonomi memiliki pengaruh yang terhadap kinerja pada usaha kecil menengah sektor ritel dengan nilai signifikansi sebesar $0.019<0,05$. Hal ini disebabkan karena pelaku UKM, banyak mengejar peluang-peluang baru dalam bisnis, mengambil resiko, berinisiatif merespon pesaing secara kompetitif untuk meningkatkan kinerja perusahaan.

Hasil ini sejalan dengan penelitian sebelumnya yang dilakukan oleh Matchaba-Hove-Vambe (2014); Hussain et. al. (2015) dan Keh et. al. (2007) yang menyatakan bahwa orientasi kewirausahaan memiliki pengaruh terhadap kinerja perusahaan, hanya saja dalam penelitian Matchaba-hove \& Vambe, hanya dimensi inovatif, agresifitas kompetitif dan proaktif saja yang memiliki pengaruh terhadap kinerja perusahaan. Hal ini disebabkan karena sebagian besar bisnis ritel di Afrika Selatan tidak memiliki komitmen untuk melakukan proyek-proyek beresiko tinggi dalam bisnis mereka, serta karyawan yang memiliki otonomi tidak mempengaruhi kesuksesan suatu bisnis.

Berdasarkan hasil dari uji t, variabel orientasi pasar memiliki pengaruh terhadap kinerja pada usaha kecil dan menengah sektor ritel dengan nilai signifikansinya sebesar $0.001<0,05$. Hal ini disebabkan karena banyak pelaku UKM berusaha untuk menciptakan nilai terbaik bagi pelanggan, memelihara loyalitas pelanggan, bersaing secara kompetitif dan memiliki koordinasi yang baik terhadap seluruh karyawan dalam bisnis mereka.

Hasil ini mendukung penelitian sebelumnya yang dilakukan oleh Narver \& Slater (1990) yang mengatakan bahwa orientasi pasar memiliki pengaruh signifikan terhadap profitabilitas usaha. Penelitian sebelumnya yang serupa dilakukan oleh Protcko \& Dornberger (2014) yang mengatakan bahwa orientasi pasar memiliki pengaruh signifikan kepada kinerja perusahaan. Protcko \& Dornberger (2014) menyatakan bahwa orientasi pasar merupakan kunci penting dalam meningkatkan kinerja bisnis. 


\section{KESIMPULAN DAN SARAN}

\section{Kesimpulan}

Berdasarkan hasil analisis data dan pembahasan, maka dapat diambil kesimpulan sebagai berikut:

a. Orientasi kewirausahaan dan orientasi pasar secara bersama-sama memiliki pengaruh terhadap kinerja pada usaha kecil dan menengah sektor ritel.

b. Orientasi kewirausahaan secara parsial memiliki pengaruh terhadap kinerja pada usaha kecil dan menengah sektor ritel.

c. Orientasi pasar secara parsial memiliki pengaruh terhadap kinerja pada usaha kecil dan menengah sektor ritel.

\section{Saran}

Untuk penelitian mendatang, lebih baik ukuran sampel diperbesar agar dapat lebih mewakili populasi dengan lebih baik, sektor yang diteliti lebih luas, tidak terbatas pada satu sektor saja serta cakupan lokasi penelitian juga dapat diperluas, tidak sebatas di wilayah Jakarta saja tapi bisa dilakukan penelitian terhadap para pelaku UKM di luar Jakarta.

\section{REFERENSI}

Farrington, S. M., Venter, E., Eybers, C. \& Boshoff, C. (2009). Task-based factors influencing the successful functioning of copreneurial businesses in South Africa. South African Journal of Economic and Management Sciences, 14(1), 24-46.

Ghozali, H. I. (2012). Aplikasi analisis multivariate dengan program IBM SPSS 20. Semarang: Badan Penerbit Universitas Diponegoro.

Hussain, J., Ismail, K. \& Shah, F. A. (2015). The effect of market and entrepreneurial orientation on organizational performance : study on Malaysian SMEs. City University Research Journal, 5(2), 203-218.

Jhonson, A. J., Dibrell, C. C., \& Hansen, E. (2009). Market orientation, innovativeness, and performance on food companies. Journal of Agri-business, 27(1/2), 85-106.

Keh. H. T., Nguyen, T. T. M. \& Hwei, P. N. (2007). The effects of entrepreneurial orientation and marketing information on the performance of SMEs. Journal of Business Venturing, 22, 592-611.

Kusumawardhani, A., McCarthy, G., \& Perera, N. (2009). Framework of entrepreneurial orientation and networking: study of SMEs performance in a developing country. Research Online University of Wollongong, 1-20.

Lotz, H. M. \& Merwe, S. P. (2013). An investigation of the influence of entrepreneurial orientation on the perceived success of agribusiness in South Africa. South African Journal of Business Management, 44(1), 15-32.

Lumpkin, G. T. \& Dess, G. G. (1996). Clarifying the entrepreneurial orientation construct and linking it to performance. The Academy of Management Review, 21(1), 135-172.

Lumpkin, G. T. \& Dess, G. G. (2001). Linking two dimension of entrepreneurial orientation to firm performance: the moderating role of environment and industry life cycle. Journal of Business Venturing, 16, 429-451.

Matchaba-Hove, T. M. \& Vambe, A. K. (2014). Entrepreneurial orientation and performance on small businesses in retail sector in the eastern cape province of South Africa. Journal of Marketing and Management, 5(2), 12-39.

Narver, J. C. \& Slater, S. F. (1990). The effect of a market orientation on business profitability. Journal of Marketing, 54, 20-35. 
Protcko, E. \& Dornberger, U. (2014). The impact of market orientation on business performance - the case of Tatarstan knowledge-intensive companies (Russia). Problem and Prespective in Management, 12(4), 225-231.

Rauch, A., Wiklund, J., Lumpkin, G. T., \& Frese, M. (2004). "Entrepreneurial orientation and business performance: assessment of past research and suggestion for the future". Paper Published in Entrepreneurial Theory and Practice, 1-54.

Samir, A. \& Larso, D. (2011). Identifikasi faktor-faktor yang mempengaruhi kinerja UKM catering di Kota Bandung. Jurnal Manajemen Teknologi, 10(2), 162-185.

Sekaran, U. \& Bougie, R. (2013). Research methods for business. New York: John Wiley \& Sons Ltd.

Shehu, A. M. (2014). Relationship between market orientation and firm performance: a look at Nigerian SMEs. Developing Country Studies, 4(12), 87-93.

Sinarasri, A. (2013). Analisis pengaruh orientasi kewirausahaan terhadap strategi bisnis dalam meningkatkan kinerja perusahaan. Prosiding Seminar Nasional 2013, 43-53.

Suliyanyo \& Rahab. (2012). The role of market orientation and learning orientation in improving innovativeness and performance of small and medium enterprises. Asian Social Science, $8(1), 134-145$.

Wang, C. L. (2008). Entrepreneurial orientation, learning orientation and firm performance. Paper Published in Entrepreneurial Theory and Practice, 1-26. 